\title{
Erratum to: Prognostic Impact of Microscopic Tumor Involved Resection Margin in Advanced Gastric Cancer Patients after Gastric Resection
}

Jung-Woo Woo $\cdot$ Keun Won Ryu $\cdot$ Ji Yeon Park $\cdot$ Bang Wool Eom •

Mi Jung Kim · Hong Man Yoon - Sook Ryun Park • Myeong-Cherl Kook •

Il Ju Choi $\cdot$ Young-Woo Kim $\cdot$ Young-Iee Park

Published online: 13 May 2014

(c) Société Internationale de Chirurgie 2014

Erratum to: World J Surg (2014) 38:439-446

DOI 10.1007/s00268-013-2301-5

The corresponding author of this paper is Keun Won Ryu.

The online version of the original article can be found under doi:10. 1007/s00268-013-2301-5.

J.-W. Woo - Y.-I. Park

Department of Surgery, Seoul National University Hospital,

Seoul, Republic of Korea

e-mail:wjfriend11@gmail.com

K. W. Ryu $(\bowtie) \cdot$ J. Y. Park · B. W. Eom .

M. J. Kim · H. M. Yoon · S. R. Park · M.-C. Kook ·

I. J. Choi · Y.-W. Kim

Gastric Cancer Branch, National Cancer Center, Madu 1-dong,

Ilsandong-gu, Goyang 410-769, Republic of Korea

e-mail: docryu@korea.com 